\title{
A TEMPORAL AND SPATIAL ANALYSIS OF ANTHROPOGENIC DRIVERS OF ENVIRONMENTAL IMPACT FOR 30 ChInese Provinces ACRoss ThreE REGIONS BETWEEN 1997 AND 2009
}

FENG HaO

University of South Florida Sarasota-Manatee

\begin{abstract}
Growing evidence has shown substantial threats to China's environment. After exceeding the United States in 2006, China became the world's largest $\mathrm{CO}_{2}$ emitter and accounted for 29 percent of global $\mathrm{CO}_{2}$ emissions in 2013. In this paper, I adopt perspectives from environmental sociology and examine the anthropogenic drivers of environmental disruption. I draw on the Impact $=$ Population $\times$ Affluence $\times$ Technology $(I P A T)$ framework and the Treadmill of Production (TOP) perspective to ground the analyses theoretically. I then analyze data for 30 Chinese provinces both temporally (from 1997 to 2009) and spatially (across the east, central, and west regions). From a temporal perspective, the findings suggest a concomitant growth of $\mathrm{CO}_{2}$ emissions, GDP per capita, and population. From a spatial perspective, Global Information System (GIS) analysis displays the overlapping of high $\mathrm{CO}_{2}$ emissions, GDP per capita, and population in East China in comparison with Central and West China. Through calculating and mapping the statistics, the GIS results can inform the spatial variations of
\end{abstract}

Feng Hao is Assistant Professor of Sociology at the University of South Florida Sarasota-Manatee. Feng's research interests include the interactions between human society and natural environment, employing multiple methods to analyze the anthropogenic ecological impact, public opinion about the environment, and the environmental movement. Contact can be directed to Feng at fenghao@sar.usf.edu.

Social Thought and Research, Vol. 34 
environmental outcomes and complement the results from longitudinal analysis. Overall, the findings confirm the IPAT framework and reinforce the TOP argument. These findings also expand the existing cross-national inquiries about climate change.

\section{Introduction}

China's environmental problems have increased substantially in recent years. China became the world's largest $\mathrm{CO}_{2}$ emitter after exceeding the United States in 2006, and accounted for 29 percent of global $\mathrm{CO}_{2}$ emissions in 2013 (Auffhammer and Carson 2008; Liu et al. 2013). The list of climate problems includes the greenhouse effect, biodiversity losses, and human-induced natural disasters. The pace of desertification has doubled since the 1970s, with deserts covering one quarter of China's territory. Forest coverage in China is 18.2 percent, well below the world average of 30.3 percent. Air pollution alone is responsible for more than 600,000 premature deaths per year (Economy 2010). China's problems have affected other countries as well. For example, its dust pollutants transport eastward to North America and its huge import of tropical rainforest timber drives global deforestation (Liu and Diamond 2005). These problems also lead to issues including "health suffering, economic losses, and social conflict" (Liu and Diamond 2008:37).

China's environmental crisis has driven scientific research about ecological deterioration and climate change. There are many underlying forces, internal and external, which affect China's sustainability. Scholars from environmental science, geography, economics, and public policy disciplines have analyzed the complexity of these forces (Liu 2010). For example, some studies have forecast the growth of China's $\mathrm{CO}_{2}$ emissions (Gregg, Andres, and Marland 2008; Wang and Watson 2010) and analyzed the decomposition of $\mathrm{CO}_{2}$ emissions (Wang, Chen, and Zou 2005). Other studies have examined the inter-regional carbon transfer across provinces (Meng et al. 2011), the contribution of urbanization and lifestyle on energy consumption (Feng, Hubacek, and Guan 2009; Zhang and Lin 2012), and the environmental impact from foreign-invested enterprises (Jiang, Zhu, and Wang 2015). 
For this study, I adopt perspectives from environmental sociology and examine the anthropogenic drivers of environmental disruption, which is an area that other disciplines have not fully explored. Environmental sociologists note that the environment is a critical dimension of human life that constrains and facilitates societies (Brulle and Dunlap 2015; Buttel 1987; Catton and Dunlap 1980; Dunlap and Catton 1979). Existing empirical studies reveal how human societies shape and are shaped by the natural environment. Human activities of production and consumption are embedded within the environmental context (Jorgenson 2013; Rosa and Dietz 2012; Shi 2003; York, Rosa, and Dietz 2003a).

I draw on the Impact $=$ Population $\times$ Affluence $\times$ Technology (IPAT) framework and the Treadmill of Production (TOP) perspective to ground the study theoretically. I then analyze data for 30 Chinese provinces. Most environmental variables vary temporally and spatially, and the data need to be merged by using time and place as integrating dimensions (Marquart-Pyatt, Jorgenson, and Hamilton 2015). Therefore, I first conduct a longitudinal analysis to understand the environmental impact from the growing economy and population. Next, I adopt the Geographic Information System (GIS) approach to display the spatial variations of $\mathrm{CO}_{2}$ emissions, economy, and population across regions. The spatial analysis is a unique contribution to the existing literature because it has not been widely used, even though some sociologists have recently taken steps to study the sophisticated questions about space and ecological context (Downey 2006).

I begin this paper by discussing China's environmental realities and relevant theoretical perspectives. Next, I introduce sources of data and variables. I then present results from temporal and spatial analyses. Finally, I summarize the findings and suggest directions for future research.

\section{China's Environmental Realities}

China has experienced ongoing transitions from a socialist economy to a market economy. The successes and failures of the transitions have prompted scholars to revisit many social scientific theories (Wu 2015). During the early stage of development, the "Great Leap Forward" movement (from 1958 to 1961) led to the loss of at least 10 percent of China's forests. The "Learn from Dazhai in 
Agriculture" movement (from 1964 to 1978) transformed numerous landscapes for crop production without considering the topographic and climate conditions (Liu 2010).

The "Reform and Open-up" policy has promoted economic growth, while the massive production for export has caused serious environmental pollution. Since the 1980s, there have been many changes, including privatization of state-owned enterprise and incorporation into the global market. Meanwhile, environmental regulations have not been revised accordingly. This is partly because of the demand of attracting foreign direct investment, which can then stimulate the economy and increase people's standard of living. In addition, loose environmental regulation is favored by domestic companies who attempt to expand their production and increase international export (Economy 2010; Shapiro 2001).

In recent years, a growing interest of environmental sustainability has led the Chinese government to reduce environmental pollution. The government has committed to drop the country's $\mathrm{CO}_{2}$ emissions intensity by 40 to 45 percent before 2020 compared with emissions in 2005. To achieve this goal, manufacturers have accelerated the transformation of adopting renewable power for production. The population growth rate has fallen from 3 percent per year in the 1950s to less than 1 percent per year in the 2010s because of the one-child policy (Watson et al. 2015). A recent publication suggests that decreased coal use in China has led to slower growth of global $\mathrm{CO}_{2}$ emissions from fossil fuels and industry (Jackson et al. 2015).

China's environmental changes provide a good opportunity to assess the environmental impact of anthropogenic activities from an environmental sociological perspective, which is an area that has not received significant attention. The changes in economic structure and demographic process are different within each province over time. In addition, because of geographic locations and other factors (e.g. government support and living conditions), some provinces have more favorable policies to stimulate economic growth and attract population migration from other provinces. Thus, I study the nuances of the environmental impacts of 30 Chinese provinces by considering both temporal and spatial heterogeneities. 


\section{Theoretical Background}

Environmental sociology highlights the relationship between society and environment. The discipline contributes to the understanding of how human activities and social institutions affect the environment (Brulle and Dunlap 2015; Rosa and Dietz 2012). In this paper, I adopt the IPAT framework to analyze the environmental impact from economic growth and population change. Because China's economy has increased steadily during the past 30 years, I also use the TOP theory to guide a focused examination of the economy's environmental impact.

\section{The IPAT Framework}

The IPAT framework was first proposed in the 1970s in response to the Ehrlich-Holdren/Commoner debate about the driving forces of environmental change (Commoner 1971; Ehrlich and Holdren 1972). The framework is still widely used in current analysis (Dietz and Rosa 1997; Dietz, Rosa, and York 2007; Rosa, York, and Dietz 2004; York, Rosa, and Dietz 2003b). Specifically, the "I" refers to environmental impact, the "P" refers to the size of population, the " $A$ " refers to economic activity, and the " $T$ " refers to the environmental impact per unit of economic activity.1

This parsimonious framework identifies the key factors that lead to environmental change and the relationships among these factors. These factors do not cause environmental impact independently and changes in one factor are multiplied by the other factors. Specifically, the literature suggests that "human population and affluence clearly contribute to enhanced environmental stress" (Rosa and Dietz 2012:581). Thus, it is necessary to consider these two factors simultaneously because one factor's stress on the environment is also conditioned by the other factor. In particular, substantial economic growth can place tremendous pressure on the environment through consumerism if the population size and growth

1 Existing studies that empirically evaluate IPAT tend to treat $\mathrm{T}$ as the error term and do not estimate it separately (Jorgenson 2013; Rosa, York, and Dietz 2004). This is because it is difficult to operationalize technology and "there is no clear consensus on valid technology indicators" (York, Rosa, and Dietz 2003a:281). I follow the tradition and include economy and population variables for this analysis. 
are also substantial. Similarly, substantial economic growth may result in less environmental pressure if the population grows at a moderate level.

The IPAT framework is not appropriate for empirical testing because it assumes the anthropogenic drivers' environmental impact is strictly proportional (i.e. an X\% change in economy leads to an $\mathrm{X} \%$ change in environmental impact). Previous studies have modified the model and suggested it can be tested by using the STIRPAT model, or Stochastic Impacts by Regression on Population, Affluence, and Technology (Dietz and Rosa 1994; Shi 2003; York, Rosa, and Dietz 2003a). The details about statistical techniques are discussed when I introduce my method of analysis.

\section{The TOP Theory}

The TOP theory argues that unfettered economic growth has a direct impact on the extraction of natural resources, the generation of waste, and environmental disruption. The treadmill is a selfreinforcing mechanism driven by capital accumulation and concentration. Profits are reinvested to expand production's scale and keep the treadmill moving. As a result, environmental disruption becomes an inevitable outcome because the production system necessitates continuous withdrawals from and additions to the environment. The escalating demand of resources (e.g. petroleum) and the limited material reserve lead to the enduring conflict between human society and the natural environment. Thus, the endless growth of the economy is inherently unsustainable and can cause ecological degradation (Schnaiberg 1980; Schnaiberg and Gould 1994).

The degradation becomes intensified when the accelerating rate of resource withdrawal exceeds the regenerative capacity of the ecological system. Manufacturers seek out new ways to enhance profits and accumulate capital. They do so by methods such as cutting wages and outsourcing, and most significantly by exploiting nature and relying on toxic and hazardous substances. Workers tend to support production expansion to avoid unemployment. The government supports and subsidizes economic growth for tax revenues, which allows it to implement policies and legitimize its rule. The social, political, and corporate elites also have sufficient 
power to prevent society from forcing manufacturers to inhibit economic expansion and internalize the environmental cost of production (Gould, Pellow, and Schnaiberg 2004, 2008; York 2004).

The TOP theory is supported by the argument of the Jevons Paradox, which asserts that improvement in production efficiency might lead to the use of less material input to generate a certain amount of output that superficially reduces environmental impacts. However, this often leads to growth in the scale and intensity of production. Consequently, the potential of making more units efficiently often paradoxically accelerates resource extraction and waste generation (Clement 2011; York and McGee 2016).2

The TOP theory is analogous to Harvey Molotch's Growth Machine Theory, which has been used to analyze urban politics and local economic development in the United States. Molotch asserted that the actors and organizations within each city share an interest in growth, which makes localities in prolonged competition with growth machines elsewhere for scarce resources. The competitions often harm the vast majority of citizens as well as their environment (Molotch 1976; Logan and Molotch 1987).

\section{Data and Measurements}

In this study, I evaluate the IPAT framework and the TOP theory empirically by analyzing data from 30 Chinese provinces between 1997 and 2009. The provincial-level statistics provide richer information than national-level statistics. This is because different provinces have various sizes and growth rates of economy and population. The dataset is balanced because it includes observations for each province in each year during this period, with a total of 390 observations (30 provinces $\times 13$ years). In comparison with an unbalanced dataset (a dataset that has missing information for several provinces in several years), a balanced dataset can minimize fluctuations in the means due to changes in the set of provinces. Thus, I do not include administrative districts (Hong Kong, Macau,

2 The paradox is named after the British economist William Stanley Jevons. Jevons revealed the production pattern of coal in the 19th century, with the efficiency of coal used for production increasing and the total coal consumption also increasing. Thus, the improvement in efficiency did not decrease overall coal consumption, but made it an attractive resource for production expansion (Clark and Foster 2001). 
and Tibet), which do not have yearly observations for variables $\left(\mathrm{CO}_{2}\right.$ emissions, GDP per capita, and population size) during this period of investigation. The list of the 30 provinces is presented in Table 1 and their corresponding geographical locations are presented in Figure 1.

\section{Dependent Variable: $\mathrm{CO}_{2}$ Emissions}

$\mathrm{CO}_{2}$ emissions are used to measure environmental quality. This is because a scientific consensus suggests that $\mathrm{CO}_{2}$ emissions are the most important greenhouse gas (IPCC 2015). The increase in $\mathrm{CO}_{2}$ concentrations has altered the chemical composition of the atmosphere and produced disruptive changes in the environment. I extracted carbon emissions data from the China Energy Statistical Yearbook (1997-2009). It records emissions produced from the consumption of major energy sources, including coal, gasoline, diesel oil, natural gas, and thermal power. The data is available for all 30 provinces. For each province, the total measurement of $\mathrm{CO}_{2}$ emissions is obtained by adding together the emissions from each

Table 1. Chinese Provinces Analyzed for this Study

\begin{tabular}{|c|c|c|}
\hline East China & Central China & West China \\
\hline Heilongjiang & Neimenggu & Xinjiang \\
\hline Jilin & Shanxi & Gansu \\
\hline Liaoning & Henan & Qinghai \\
\hline Beijing & Anhui & Ningxia \\
\hline Tianjin & Hubei & Shaanxi \\
\hline Hebei & Hunan & Sichuan \\
\hline Shandong & Jiangxi & Chongqing \\
\hline Jiangsu & Guangxi & Guizhou \\
\hline Shanghai & & Yunnan \\
\hline Zhejiang & & \\
\hline Fujian & & \\
\hline Guangdong & & \\
\hline Hainan & & \\
\hline
\end{tabular}

Note: The provinces for each region are arranged according to their geographical locations from north to south as presented in Figure 1. 


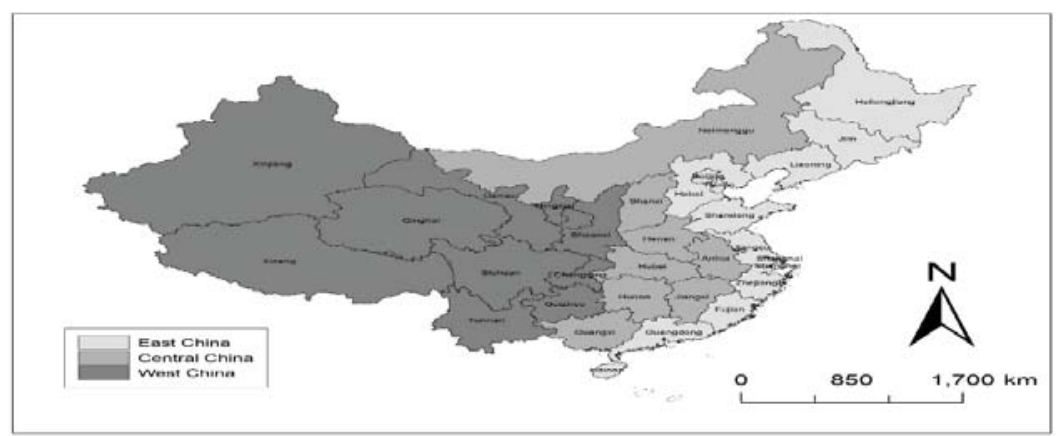

Figure 1. Geographic Location of Chinese Provinces across Three Regions

energy type. Previous studies on China's environmental subjects used the same approach to calculate $\mathrm{CO}_{2}$ emissions (Meng et al. 2011; Zhang and Lin 2012).3

\section{Independent Variables: GDP Per Capita and Population}

GDP per capita is used to measure the economic situation for each province. This data was extracted from the China Statistical Yearbook (1997-2009). The data has been adjusted by the consumer price index, which is necessary because it controls for inflation and produces the real GDP per capita. The population data for each of the 30 provinces is also extracted from the China Statistical Yearbook (1997-2009).

Between 1997 and 2009, total $\mathrm{CO}_{2}$ emissions for the 30 provinces increased from 2.92 billion tons to 7.14 billion tons. National GDP per capita increased more than three times, from $¥ 7,200$ to $¥ 25,995$. Population increased from 1.22 billion to 1.31 billion during this period.4 Even though the population's growth rate is smaller than the other variables, its gigantic size can still lead to significant environmental changes. Also, because population is a critical component of the IPAT framework and is included in

3 A detailed description of the $\mathrm{CO}_{2}$ emissions data can be found in a study by Meng and colleagues (2011).

4 The exchange rate between the RMB and the U.S. dollar was 7.77 in 2009, which means $\$ 1$ equals approximately $¥ 7.8$. 
previous studies on this subject, I included the variable for the current analysis. The correlation statistics among these three variables are presented as a matrix in Table 2.5

\section{Temporal Analysis of Anthropogenic Drivers of Environmental Impact}

The first objective of this paper is to estimate the environmental impact for the 30 Chinese provinces over 13 years. Previous crossnational studies on this subject by Jorgenson and colleagues used the time-series cross-sectional Prais-Winsten (PW) regression with panel-corrected standard errors. They allow for variations that are heteroskedastic and contemporaneously correlated across panels. They also use the AR(1) process for all panels because of the lack of theoretical justification for treating it as panel-specific (Jorgenson 2013; Jorgenson and Clark 2016). The regression model is analogous to the STIRPAT model to assess the IPAT framework. Other studies with specific focuses on European Union countries, South and East Asian countries, or Former Soviet Union countries also used this approach for statistical estimation (York 2007a; 2007b; 2008).

I follow those studies and use PW regression for analysis. I also follow the tradition to include both case-specific intercepts and period-specific intercepts, which makes the model analogous to estimating a two-way fixed effects model (Allison 2009). In particular, I regress the $\mathrm{CO}_{2}$ emissions for each province in each year

Table 2. Correlation Matrix for $\mathrm{CO}_{2}$ Emissions, GDP Per Capita, and Population

\begin{tabular}{|c|c|c|c|}
\hline & $\mathrm{CO}_{2}$ Emissions & GDP Per Capita & Population \\
\hline $\mathrm{CO}_{2}$ Emissions & 1.00 & & \\
\hline GDP Per Capita & 0.31 & 1.00 & \\
\hline Population & 0.64 & -0.12 & 1.00 \\
\hline
\end{tabular}

5 One cause for the negative correlation between GDP per capita and population might be that the populous provinces (e.g. Henan and Shandong) tend to focus on agriculture or labor-intensive industries, which generate less GDP in comparison with coastal provinces that focus on other industries such as finance, technology, and international trade. 
on two independent variables: GDP per capita and population. The components of the model are displayed in Table 3.

I employ dummy variables for each province and each time point to control for $u_{i}$ and $w_{t}$. The dummy coding of each province $\left(u_{i}\right)$ controls for potential unobserved heterogeneity that is temporally invariant within provinces, and the dummy coding of each period $\left(\mathrm{w}_{\mathrm{t}}\right)$ controls for potentially unobserved heterogeneity that is cross-sectionally invariant within periods. Thus, this modeling approach is "robust against potentially omitted control variables and more closely approximates experimental conditions than other panel model approaches" (Jorgenson and Clark 2012:13).6

The results in Table 4 present the unstandardized regression coefficients with robust standard errors shown in parentheses and statically significant parameter estimates indicated using asterisks. All variables in the model, except dummy variables, are in logarithmic form, and thus the model estimates elasticity coefficients. Given that this is an elasticity model, the coefficients indicate the percent change in the dependent variable in response to

Table 3. Prais-Winsten Regression Formula and its Components

\begin{tabular}{|c|l|}
\hline Formula & $\mathrm{Y}_{\mathrm{it}}=\beta \mathrm{X}_{\mathrm{it}}+\mathrm{u}_{\mathrm{i}}+\mathrm{w}_{\mathrm{t}}+\mathrm{e}_{\mathrm{it}}$ \\
\hline $\mathrm{Y}_{\mathrm{it}}$ & $\begin{array}{l}\text { Dependent variable }\left(\mathrm{CO}_{2} \text { emissions) for each }\right. \\
\text { province at each year. }\end{array}$ \\
\hline$\beta \mathrm{X}_{\mathrm{it}}$ & $\begin{array}{l}\text { Independent variables (GDP per capita and } \\
\text { population) that vary over time. }\end{array}$ \\
\hline $\mathrm{u}_{\mathrm{i}}$ & $\begin{array}{l}\text { The case-specific disturbance term that is constant } \\
\text { over time. }\end{array}$ \\
\hline $\mathrm{w}_{\mathrm{t}}$ & $\begin{array}{l}\text { The period-specific disturbance term that is constant } \\
\text { across provinces. }\end{array}$ \\
\hline $\mathrm{e}_{\mathrm{it}}$ & $\begin{array}{l}\text { The disturbance term unique to each province at } \\
\text { each time point. }\end{array}$ \\
\hline
\end{tabular}

Note: The subscript ${ }_{i}$ represents the case of analysis (each province) and the subscript ${ }_{t}$ represents the time period (between 1997 and 2009).

6 A detailed description of this statistical technique can be found in the Materials and Methods section of Jorgenson and Clark (2013) to analyze the environment/population interactions. 
Table 4. Prais-Winsten Regression Results with $\mathrm{CO}_{2}$ Emissions Regressed on GDP Per Capita and Population Size for 30 Provinces of China between 1997 and 2009

\begin{tabular}{lll}
\hline & Model 4.1 & Model 4.2 \\
\hline GDP per capita & $0.54(0.12)^{* * *}$ & $0.73(0.12)^{* * *}$ \\
\hline Population & $0.42(0.13)^{* *}$ & $0.81(0.25)^{* *}$ \\
\hline INTERACTION VARIABLES & & \\
\hline GDP per capita $\times \mathbf{1 9 9 8}$ & & $0.01(0.01)$ \\
GDP per capita $\times \mathbf{1 9 9 9}$ & & $0.03(0.01)^{* * *}$ \\
\hline GDP per capita $\times \mathbf{2 0 0 0}$ & & $0.05(0.02)^{* *}$ \\
\hline GDP per capita $\times \mathbf{2 0 0 1}$ & & $0.01(0.01)$ \\
\hline GDP per capita $\times \mathbf{2 0 0 2}$ & & $-0.03(0.01)^{*}$ \\
\hline GDP per capita $\times \mathbf{2 0 0 3}$ & & $-0.10(0.01)^{* * *}$ \\
\hline GDP per capita $\times \mathbf{2 0 0 4}$ & & $-0.07(0.02)^{* * *}$ \\
GDP per capita $\times \mathbf{2 0 0 5}$ & & $-0.10(0.02)^{* * *}$ \\
\hline GDP per capita $\times \mathbf{2 0 0 6}$ & & $-0.14(0.03)^{* * *}$ \\
GDP per capita $\times \mathbf{2 0 0 7}$ & & $-0.13(0.03)^{* * *}$ \\
\hline GDP per capita $\times \mathbf{2 0 0 8}$ & & $-0.15(0.03)^{* * *}$ \\
GDP per capita $\times \mathbf{2 0 0 9}$ & -3.51 & $-0.19(0.04)^{* * *}$ \\
Constant & 0.97 & -8.51 \\
R & 390 & 0.97 \\
\hline Overall N & 0.86 & 390 \\
\hline Rho & & 0.65 \\
\hline
\end{tabular}

Note: ${ }^{*} p<.05 ;{ }^{* *} p<.01 ;{ }^{* * *} p<.001$, two-tailed tests

a 1 percent change in the independent variable, controlling for other variables in the model (Wooldridge 2006).7

The analysis produces multiple theoretically relevant findings. First, the effects of GDP per capita and population on $\mathrm{CO}_{2}$ emissions are positive and statistically significant. As displayed in Model 4.1, a 1 percent increase in GDP per capita leads to a 0.54 percent increase in $\mathrm{CO}_{2}$ emissions, and a 1 percent increase in population

7 I performed several tests to check for the violation of modeling assumptions. First, I used the Variance Inflation Factor (VIF) estimates to test for multicollinearity. The mean VIF is 1.01 , which indicates that multicollinearity is not a likely concern. Second, to test for potential influential cases, I estimated the model by excluding each province in turn. The results are similar across models with the two independent variables being significant and positive. I excluded each year in turn and the results are also similar across models. This indicates that there are no particularly influential cases. In addition, I estimated the first-difference baseline model to assess whether the PW regression model estimates are spurious. The results are consistent and indicate that this analysis is not biased. 
leads to a 0.42 percent increase in $\mathrm{CO}_{2}$ emissions. The findings confirm the IPAT framework and the TOP theory. Specifically, the simultaneous increase of the economy and population led to the consumption of fossil fuels and $\mathrm{CO}_{2}$ emissions for the 30 Chinese provinces.

Because China's economy grows fast and its GDP per capita increased more than three times between 1997 and 2009, I conducted a focused examination of the TOP theory and the economy's environmental impact. I followed the studies by Jorgenson and colleagues to incorporate interactions between GDP per capita and year. These interactions help assess the magnitude of the economy's impact on $\mathrm{CO}_{2}$ emissions (Jorgenson and Clark 2012; Jorgenson, Clark, and Giedraitis 2012). The year of 1997 is used as the reference year. For models that have interaction variables, the coefficient for GDP per capita represents the percent change in $\mathrm{CO}_{2}$ emissions for each percent change in the independent variable in 1997. The impact of GDP per capita on $\mathrm{CO}_{2}$ emissions for other time points (from 1998 to 2009) equals the sum of the coefficient plus the interaction term if the latter is statistically significant. An insignificant term means the impact in the later time point is not different from the impact in 1997.

The findings in Model 4.2 suggest that the magnitude of the impact from GDP per capita on $\mathrm{CO}_{2}$ emissions varies through time. The interactions between GDP per capita and time points are positive at the beginning, and then turn negative from 2002 to 2009. Specifically, a 1 percent increase in GDP per capita predicts a 0.73 percent increase in $\mathrm{CO}_{2}$ emissions in 1997, a 0.78 percent increase in 2000 , and a 0.54 percent increase in 2009 . Though results indicate that the magnitude of the economy's impact has decreased, the degree of the decrease is minimal. It cannot reverse the economy's impact on the environment from disruptive to non-disruptive in the near future. The fluctuation of the regression coefficients is also presented in Figure 2.8

The relatively high $\mathrm{R}^{2}$ (they equal 0.97 in these three models) is a function of the case-specific and period-specific intercepts

8 In an unreported analysis that has the interaction variables between population and $\mathrm{CO}_{2}$ emissions, I found that the population's impact remains relatively constant during this period, with the elasticity coefficients equaling 0.47 at both the starting and ending points. 
included in the model. This is analogous with findings from other studies using similar regression models (Jorgenson and Clark 2012; York 2007a). It also indicates that economic and demographic factors provide a reasonably thorough explanation of $\mathrm{CO}_{2}$ emissions for the 30 Chinese provinces between 1997 and 2009.

\section{Spatial Analysis of Interactions among Environment, Economy, and Population}

The second objective of this paper is to assess the anthropogenic environmental impact from a spatial perspective and to examine whether $\mathrm{CO}_{2}$ emissions are concentrated in areas where GDP per capita and population size are enormous. The 30 provinces are divided into three regions (East China, Central China, and West China) as presented in Table 1 and Figure 1. This method of grouping provinces is common in existing studies because it takes the different geographic locations and various levels of development into consideration (Meng et al. 2011; Zhang and Lin 2012).

I entered the data into ArcGIS software and generated maps to display the spatial distribution of the three indicators in both 1997 and 2009, which are the beginning and ending years of the data frame. The quantile classification approach is used to divide the

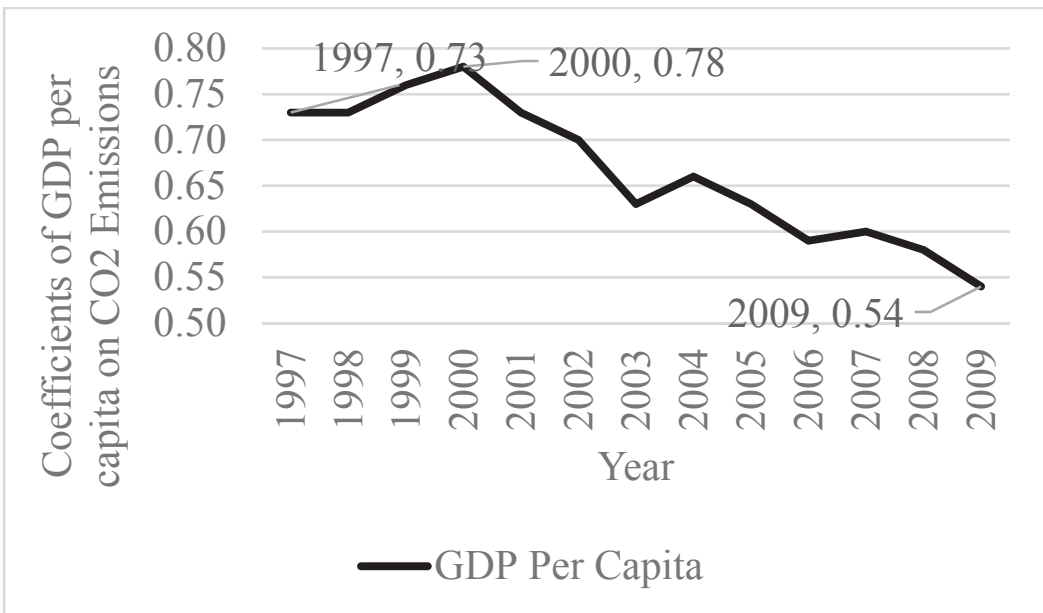

Figure 2. Estimated Regression Coefficients of GDP Per Capita on $\mathrm{CO}_{2}$ Emissions from 1997 to 2009. 
provinces equally into three groups with 10 provinces in each region. Provinces with higher $\mathrm{CO}_{2}$ emissions, GDP per capita, and population are represented with larger bubbles in the maps.

As presented in Figure 3, most provinces along the coastal line have a high amount of $\mathrm{CO}_{2}$ emissions. The largest size bubble represents the provinces that had $\mathrm{CO}_{2}$ emissions over 113 million tons in 1997 or over 277 million tons in 2009. Hebei, Jiangsu, and Shandong in East China had the most $\mathrm{CO}_{2}$ emissions among all 30 provinces in both 1997 and 2009. In 1997, East China had 1,468 million tons of $\mathrm{CO}_{2}$ emissions, Central China had 880 million tons of $\mathrm{CO}_{2}$ emissions, and West China had 571 million tons of $\mathrm{CO}_{2}$ emissions. In 2009, the 13 provinces in East China had 3,555 million tons of $\mathrm{CO}_{2}$ emissions, which almost equaled the emissions from the provinces in Central and West China (3,583 million tons). From another perspective, 851 tons of $\mathrm{CO}_{2}$ emissions was generated in each square kilometer in East China, compared with 142 tons in each square kilometer in West China in 1997. Similarly, the numbers became 2,074 tons per square kilometer compared with 336 tons per square kilometer in 2009.
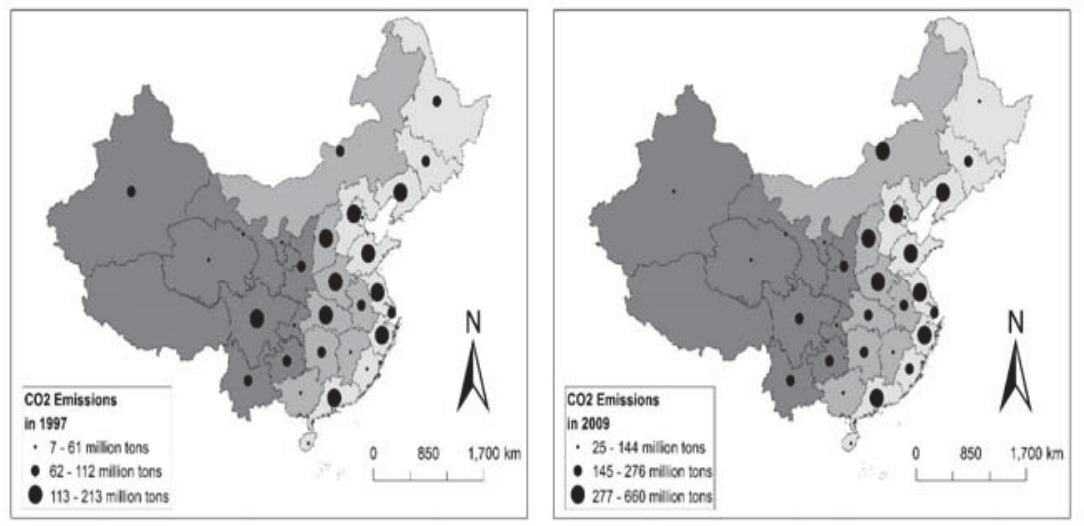

Figure 3. Spatial Distribution of $\mathrm{CO}_{2}$ Emissions for the 30 Provinces across the Three Regions in 1997 and 2009 

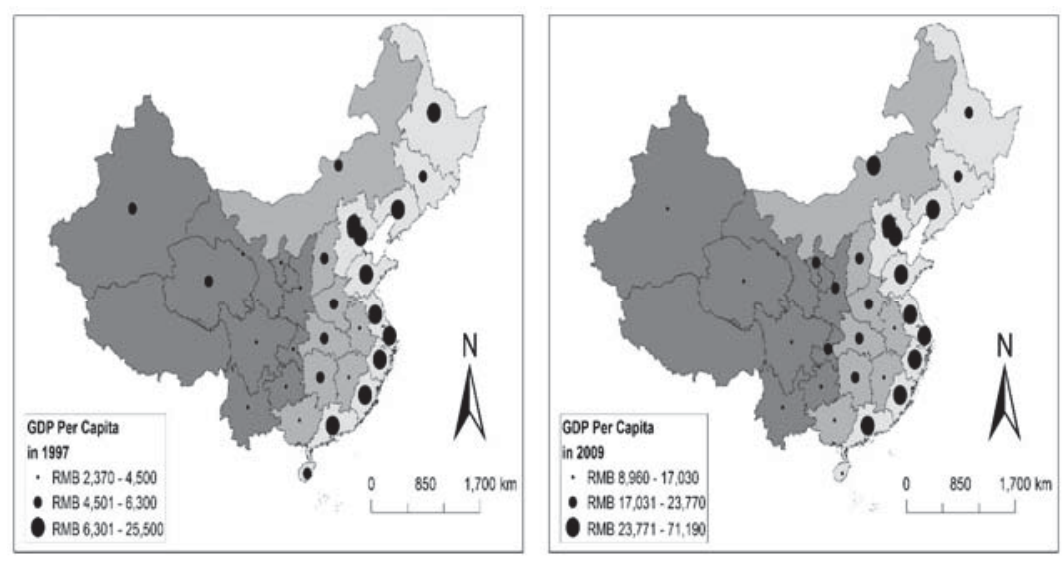

Figure 4. Spatial Distribution of GDP Per Capita for the 30 Provinces across the Three Regions in 1997 and 2009

In Figure 4, the largest size bubble represents the ten provinces that had GDP per capita over $¥ 6,301$ in 1997 or over $¥ 23,771$ in 2009, which are all located in East China, except for Neimenggu in 2009. Provinces around the Bohai Bay Area (e.g. Beijing, Hebei, and Shandong) and the Yangtze Delta (e.g. Jiangsu, Shanghai and Zhejiang) enjoy favorable policies such as tax reductions and state funding for infrastructure development. Provinces around the Pearl River Delta (e.g. Guangdong and Fujian) are close to Hong Kong, Macao, Taiwan, and Southeast Asia. This advantageous geographic location promotes export-oriented industries, international trade, and foreign investment.

Figure 5 presents the spatial distribution of population with the largest size bubble representing the provinces that had populations over 45 million in 1997 or over 49 million in 2009. Guangdong (96 million), Shandong (94 million), Jiangsu (77 million), and Hebei (70 million) in East China are the top populous provinces in comparison with the population size for Qinghai (5.6 million) and Ningxia (6.3 million) in West China. The prosperous economic growth and better living environment in East China can account for their large population size. In 1997, 521 million people resided in East China, while only 283 million resided in West China, even though West China has more space. The unequal spatial distribution of population 

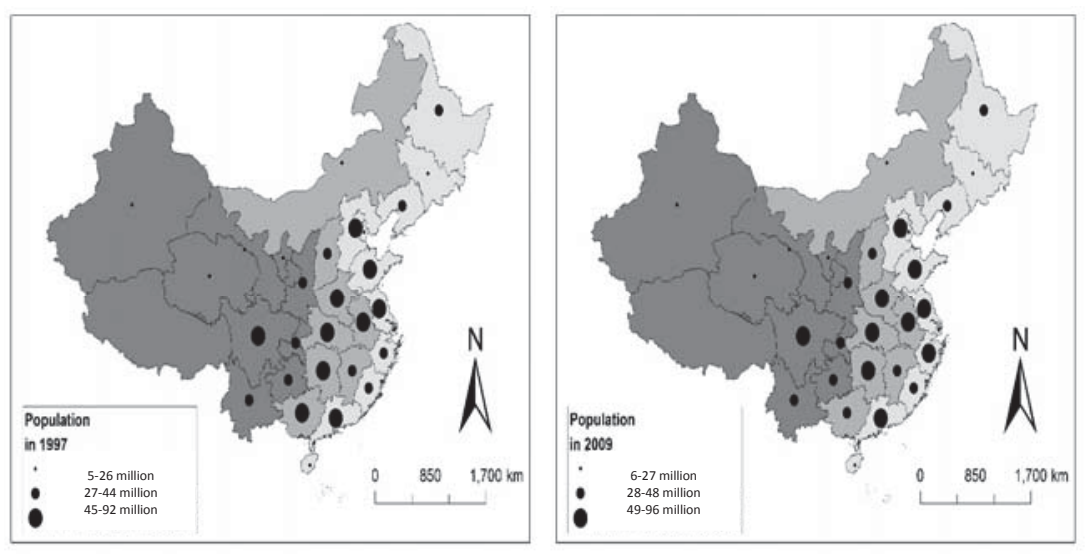

Figure 5. Spatial Distribution of Population for the 30 Provinces across the Three Regions in 1997 and 2009

remained in 2009, with 593 million people residing in East China and 292 million residing in West China.

Overall, I find the overlapping of high $\mathrm{CO}_{2}$ emissions, GDP per capita, and population in East China, which complement and reinforce the outcome from the longitudinal analysis. In addition to the maps, the changes of the three indicators for each province between the 1997 and 2009 are presented in Table 5.

\section{Discussion and Conclusion}

The pressing environmental problems in China compel the scientific community to direct more attention to the relationships between human society and the natural environment. Environmental sociology theories perceive environmental problems as a social issue that constrains the development of human society. The main purpose of this paper is to evaluate the IPAT framework through analyzing data for 30 Chinese provinces. I also focus on examining the economy's environmental impact and assessing the perspectives of the TOP theory.

First, there is a concomitant increase in $\mathrm{CO}_{2}$ emissions, GDP per capita, and population size for the 30 provinces between 1997 and 2009. More importantly, there is still an ongoing accumulation of $\mathrm{CO}_{2}$ emissions, although its growth rate is not proportional with the 
growth rate of economy and population.9 Second, the spatial analysis displays that East China has the largest size of GDP per capita and population, which together contribute to the highest concentration of $\mathrm{CO}_{2}$ emissions in this region.10

Table 5. The Change of $\mathrm{CO}_{2}$ Emissions, GDP Per Capita, and Population between 1997 and 2009 for 30 Chinese Provinces

\begin{tabular}{|c|c|c|c|c|c|c|}
\hline Province & $\begin{array}{c}\mathrm{CO}_{2} \\
\text { Emissions } \\
1997\end{array}$ & $\begin{array}{c}\mathrm{CO}_{2} \\
\text { Emissions } \\
2009\end{array}$ & $\begin{array}{c}\text { GDP } \\
\text { Per } \\
\text { Capita } \\
1997\end{array}$ & $\begin{array}{c}\text { GDP Per } \\
\text { Capita } \\
2009\end{array}$ & $\begin{array}{c}\text { Population } \\
1997\end{array}$ & $\begin{array}{c}\text { Population } \\
2009\end{array}$ \\
\hline \multicolumn{7}{|l|}{ East China } \\
\hline Beijing & 61 & 83 & $¥ 18,560$ & $¥ 64,790$ & 12 & 18 \\
\hline Fujian & 45 & 188 & $¥ 9,280$ & $¥ 30,990$ & 33 & 36 \\
\hline Guangdong & 145 & 405 & $¥ 11,190$ & $¥ 37,630$ & 71 & 96 \\
\hline Hainan & 7 & 25 & $¥ 5,560$ & $¥ 16,910$ & 7 & 9 \\
\hline Hebei & 213 & 541 & $¥ 6,300$ & $¥ 21,820$ & 65 & 70 \\
\hline Heilongjiang & 112 & 144 & $¥ 7,210$ & $¥ 19,760$ & 38 & 38 \\
\hline Jiangsu & 182 & 459 & $¥ 9,850$ & $¥ 40,120$ & 71 & 77 \\
\hline Jilin & 99 & 168 & $¥ 5,760$ & $¥ 23,770$ & 26 & 27 \\
\hline Liaoning & 154 & 308 & $¥ 8,940$ & $¥ 31,630$ & 41 & 43 \\
\hline Shandong & 187 & 660 & $¥ 7,920$ & $¥ 32,240$ & 88 & 95 \\
\hline Shanghai & 96 & 169 & $¥ 25,500$ & $¥ 71,190$ & 15 & 19 \\
\hline Tianjin & 53 & 107 & $¥ 13,750$ & $¥ 55,480$ & 10 & 12 \\
\hline Zhejiang & 114 & 298 & $¥ 11,150$ & $¥ 40,740$ & 44 & 52 \\
\hline \multicolumn{7}{|l|}{$\begin{array}{c}\text { Central } \\
\text { China }\end{array}$} \\
\hline Anhui & 107 & 235 & $¥ 4,050$ & $¥ 14,640$ & 61 & 61 \\
\hline Guangxi & 52 & 136 & $¥ 3,990$ & $¥ 14,100$ & 46 & 49 \\
\hline Henan & 163 & 454 & $¥ 4,520$ & $¥ 18,070$ & 92 & 95 \\
\hline Hubei & 139 & 276 & $¥ 5,110$ & $¥ 20,110$ & 59 & 57 \\
\hline Hunan & 103 & 216 & $¥ 4,890$ & $¥ 18,020$ & 65 & 64 \\
\hline Jiangxi & 52 & 116 & $¥ 4,080$ & $¥ 15,460$ & 42 & 44 \\
\hline Neimenggu & 97 & 438 & $¥ 5,400$ & $¥ 35,920$ & 23 & 24 \\
\hline Shanxi & 167 & 371 & $¥ 5,100$ & $¥ 18,850$ & 31 & 34 \\
\hline \multicolumn{7}{|l|}{ West China } \\
\hline Chongqing & 57 & 128 & $¥ 4,410$ & $¥ 20,510$ & 30 & 29 \\
\hline Gansu & 54 & 100 & $¥ 3,350$ & $¥ 10,980$ & 25 & 26 \\
\hline Guizhou & 85 & 209 & $¥ 2,370$ & $¥ 8,960$ & 36 & 38 \\
\hline Ningxia & 21 & 81 & $¥ 4,500$ & $¥ 18,440$ & 5 & 6 \\
\hline Qinghai & 13 & 34 & $¥ 4,540$ & $¥ 15,850$ & 5 & 6 \\
\hline Shaanxi & 78 & 195 & $¥ 3,880$ & $¥ 18,990$ & 36 & 38 \\
\hline Sichuan & 136 & 258 & $¥ 4,170$ & $¥ 15,070$ & 84 & 82 \\
\hline Xinjiang & 64 & 144 & $¥ 6,300$ & $¥ 17,030$ & 17 & 22 \\
\hline
\end{tabular}

9 The growth rate for $\mathrm{CO}_{2}$ emissions is not proportional with the growth rate of economy and population because the regression coefficient is less than 1.0. Each 1 percent increase in either of the independent variables leads to less than 1 percent increase in the dependent variable.

10 In addition to economic growth and population size, the coastal location might also be a reason that leads to the industrialization of the region and thus environmental disruption. 
With respect to method, the longitudinal analysis takes the temporal nuances of the growth of $\mathrm{CO}_{2}$ emissions, economy, and population into consideration. I also give broader attention to the spatial analytical techniques. In particular, the GIS method can inform the variations of environmental outcomes across provinces through calculating and mapping the statistics. This can complement the results from regression analysis.

Most existing studies on the human dimensions of climate change have analyzed cross-national data and contributed immensely to our understanding of this subject (Jorgenson and Clark 2012; Rosa and Dietz 2012; York, Rosa, and Dietz 2003a). Nevertheless, this line of research can be improved through empirical assessment of specific regions and countries throughout the world. I contribute to this endeavor by analyzing data from China, which has the highest $\mathrm{CO}_{2}$ emissions in the world.

Overall, I analyze data for 30 Chinese provinces across three regions between 1997 and 2009. Even though all provinces experienced increases in $\mathrm{CO}_{2}$ emissions, GDP per capita, and population, I find the increases have notably temporal and regional differences. The findings confirm the IPAT framework and reinforce the TOP argument, and can expand and complement the existing scientific inquiries about climate change.

The findings from this paper might lead to other analyses of several typical provinces (e.g. Shanghai, Beijing, or Guangdong in the coastal area). The growing number of affluent Chinese, which might increase consumerism and $\mathrm{CO}_{2}$ emissions, can be another subject for future research. Putting the analysis of China within the global context might generate additional implications (Hao 2014a). Subsequent studies on this subject that have complete data for more control variables will complement the current findings and generate additional implications. Studies that analyze the impact on a variety of additional environmental outcomes (e.g. ecological footprint) would also be valuable. In addition to identifying patterns of China's pollution, research might also examine potential solutions for addressing the environmental crisis. This might include exploration of how climate change interacts with social norms (Hao 2014b), investigation of the benefits of adopting leading eco-friendly technologies (Jiang, Zhu, and Wang 2015), and interdisciplinary 
research of how to translate proposals into workable actions ( $\mathrm{Ru}$ and Ortolano 2009).

\section{Acknowledgements}

The author would like to express gratitude to Dr. Don A. Dillman and two anonymous reviewers of the journal for their insightful comments. 


\section{References}

Allison, Paul D. 2009. Fixed Effects Regression Models. Thousand Oaks, CA: SAGE Publications.

Auffhammer, Maximilian and Richard T. Carson. 2008.

"Forecasting the Path of China's $\mathrm{CO}_{2}$ Emissions Using Province-level Information." Journal of Environmental Economics and Management 55(3):229-247.

Brulle, Robert J. and Riley E. Dunlap. 2015. "Sociology and Global Climate Change: Introduction.” Pp. 1-31 in Climate Change and Society, edited by R. E. Dunlap and R. Brulle. New York: Oxford University Press.

Buttel, Frederick H. 1987. "New Directions in Environmental Sociology." Annual Review of Sociology 13:465-488.

Catton Jr., William. R. and Riley E. Dunlap. 1980. "A New Ecological Paradigm for Post-Exuberant Sociology." American Behavioral Scientist 24(1):15-47.

Clark, Brett and John B. Foster. 2001. "William Stanley Jevons and the Coal Question: An Introduction to Jevons's 'Of the Economy of Fuel."' Organization and Environment 14(1):9398.

Clement, Matthew T. 2011. "The Jevons Paradox and Anthropogenic Global Warming: A Panel Analysis of StateLevel Carbon Emissions in the United States, 19631997." Society \& Natural Resources 24(9):951-961.

Commoner, Barry. 1971. The Closing Circle: Nature, Man and Technology. New York: Alfred A. Knopf.

Dietz, Thomas and Eugene A. Rosa. 1994. "Rethinking the Environmental Impacts of Population, Affluence and Technology." Human Ecology Review 1/2:277-300.

Dietz, Thomas and Eugene A. Rosa. 1997. "Effects of Population and Affluence on $\mathrm{CO}_{2}$ Emissions." Proceedings of the National Academy of Sciences of the United States of America 94(1):175-179.

Dietz, Thomas, Eugene A. Rosa, and Richard York. 2007. "Driving the Human Ecological Footprint." Frontiers in Ecology and the Environment 5(1):13-18. 
Downey, Liam. 2006. "Using Geographic Information Systems to Reconceptualize Spatial Relationships and Ecological Context." American Journal of Sociology 112(2):567-612.

Dunlap, Riley E. and William R. Catton Jr. 1979. "Environmental Sociology." Annual Review of Sociology 5:243-273.

Economy, Elizabeth C. 2010. The River Runs Black: The Environmental Challenge to China's Future. Ithaca, NY: Cornell University Press.

Ehrlich, Paul R. and John P. Holdren. 1972. "A Bulletin Dialogue on the 'Closing Circle': Critique: One-Dimensional Ecology." Bulletin of the Atomic Scientists 28(5):16-27.

Feng, Kuishuang, Klaus Hubacek, and Dabo Guan. 2009.

"Lifestyles, Technology and $\mathrm{CO}_{2}$ Emissions in China: A Regional Comparative Analysis." Ecological Economics 69(1):145-154.

Gould, Kenneth A., David N. Pellow, and Allan Schnaiberg. 2004. "Interrogating the Treadmill of Production: Everything You Wanted to Know about the Treadmill but Were Afraid to Ask." Organization and Environment 17(3):296-316.

Gould, Kenneth A., David N. Pellow, and Allan Schnaiberg. 2008. The Treadmill of Production: Injustice and Unsustainability in the Global Economy. Boulder, CO: Paradigm.

Gregg, Jay S., Robert J. Andres, and Gregg Marland. 2008. "China: Emissions Pattern of the World Leader in CO Emissions from Fossil Fuel Consumption and Cement Production." Geophysical Research Letters 35(8):1-5.

Hao, Feng. 2014a. "Material Extraction/Consumption and Global Trade: An Empirical Examination for 95 Countries between 1980 and 2009." Perspectives on Global Development and Technology 13(4):423-443.

Hao, Feng. 2014b. "The Effect of Economic Affluence and Ecological Degradation on Chinese Environmental Concern: A Multilevel Analysis." Journal of Environmental Studies and Sciences 4(2):123-131.

Intergovernmental Panel on Climate Change (IPCC). 2015. Fifth Assessment Report. 
Jackson, Robert B., Josep G. Canadell, Corinne Le Quéré, Robbie M. Andrew, Jan Ivar Korsbakken, Glen P. Peters, and Nebojsa Nakicenovic. 2016. "Reaching Peak Emissions." Nature Climate Change 6:7-10.

Jiang, X., K. Zhu, and S. Wang. 2015. "The Potential for Reducing China's Carbon Dioxide Emissions: Role of Foreign-Invested Enterprises." Global Environmental Change 35(15):22-30.

Jorgenson, Andrew K. 2013. "Population, Affluence, and Greenhouse Gas Emissions: The Continuing Significance of Structural Human Ecological and the Utility of STIRPAT.” Pp. 139-151 in Structural Human Ecology: New Essays in Risk, Energy, and Sustainability, edited by T. Dietz and A. K. Jorgenson. Pullman, WA: Washington State University Press.

Jorgenson, Andrew K. and Brett Clark. 2012. "Are the Economy and the Environment Decoupling? A Comparative International Study, 1960-2005." American Journal of Sociology 118(1):1-44.

Jorgenson, Andrew K. and Brett Clark. 2013. "The Relationship between National-level Carbon Dioxide Emissions and Population Size: An Assessment of Regional and Temporal Variation, 1960-2005." PLOS ONE 8(2):1-8.

Jorgenson, Andrew K. and Brett Clark. 2016. "The Temporal Stability and Developmental Differences in the Environmental Impacts of Militarism: The Treadmill of Destruction and Consumption-Based Carbon Emissions." Sustainability Science 11(3):505-514.

Jorgenson, Andrew K., Brett Clark, and Vincent R. Giedraitis. 2012. "The Temporal (In)Stability of the Carbon Dioxide Emissions/Economic Development Relationship in Central and Eastern European Nations." Society \& Natural Resources 25:1182-1192.

Liu, Jianguo. 2010. "Environment. China's Road to Sustainability." Science 328(5974):50.

Liu, Jianguo and Jared Diamond. 2005. "China's Environment in a Globalizing World-How China and the Rest of the World Affect Each Other." Nature 435(7046):1179-1186.

Liu, Jianguo and Jared Diamond. 2008. "Revolutionizing China's Environmental Protection.” Science 319(5859):37-38. 
Liu, Zhu, Dabo Guan, Douglas Crawford-Brown, Qiang Zhang, Kebin He, and Jianguo Liu. 2013. "Energy Policy: A Lowcarbon Road Map for China.” Nature 500(7461):143-145.

Logan, John R. and Harvey L. Molotch. 1987. Urban Fortunes: The Political Economy of Place. Berkeley, CA: University of California Press.

Marquart-Pyatt, Sandra T., Andrew K. Jorgenson, and Lawrence C. Hamilton. 2015. "Methodological Approaches for Sociological Research on Climate Change." Pp. 369-411 in Climate Change and Society: Sociological Perspectives, edited by R. E. Dunlap and R. Brulle. New York: Oxford University Press.

Meng, Lei, Ju'e Guo, Jian Chai, and Zengkai Zhang. 2011. "China's Regional $\mathrm{CO}_{2}$ Emissions: Characteristics, InterRegional Transfer and Emission Reduction Policies." Energy Policy 39(10):6136-6144.

Molotch, Harvey L. 1976. "The City as a Growth Machine: Toward a Political Economy of Place." American Journal of Sociology 82(2):309-332.

National Bureau of Statistics of China. 1997-2009. China Energy Statistical Yearbook. Beijing, China: China Statistics Press.

National Bureau of Statistics of China. 1997-2009. China Statistical Yearbook. Beijing, China: China Statistics Press.

Rosa, Eugene A. and Thomas Dietz. 2012. "Human Drivers of National Greenhouse-Gas Emissions." Nature Climate Change 2(8):581-586.

Rosa, Eugene A., Richard York, and Thomas Dietz. 2004. "Tracking the Anthropogenic Drivers of Ecological Impacts." AMBIO: A Journal of the Human Environment 33(8):509-512.

$\mathrm{Ru}$, Jiang and Leonard Ortolano. 2009. "Development of CitizenOrganized Environmental NGOs in China." Voluntas:

International Journal of Voluntary and Nonprofit Organizations 20(2):141-168.

Schnaiberg, Allan. 1980. The Environment: From Surplus to Scarcity. New York: Oxford University Press.

Schnaiberg, Allan and Kenneth A. Gould. 1994. Environment and Society: The Enduring Conflict. New York: St. Martin's. 
Shapiro, Judith. 2001. Mao's War Against Nature: Politics and the Environment in Revolutionary China. Cambridge, UK:

Cambridge University Press.

Shi, Anqing. 2003. "The Impact of Population Pressure on Global Carbon Dioxide Emissions, 1975-1996: Evidence from Pooled Cross-country Data." Ecological Economics 44(1):29-42.

Wang, Can, Jining Chen, and Ji Zou. 2005. "Decomposition of Energy-related $\mathrm{CO}_{2}$ Emission in China: 1957-2000.” Energy 30(1):73-83.

Wang, Tao and Jim Watson. 2010. "Scenario Analysis of China's Emissions Pathways in the 21st Century for Low Carbon Transition." Energy Policy 38(7):3537-3546.

Watson, Jim, Bob Byrne, David Ockwell, and Michele Stua. 2015. "Lessons from China: Building Technological Capabilities for Low Carbon Technology Transfer and Development." Climatic Change 131(3):387-399.

Wooldridge, Jeffrey M. 2006. Introductory Econometrics: A Modern Approach. Mason, OH: South-Western.

Wu, Xiaogang. 2015. "Towards a Professional Sociology on China." Chinese Journal of Sociology 1(1):6-14.

York, Richard. 2004. "The Treadmill of (Diversifying) Production." Organization \& Environment 17(3):355-362.

York, Richard. 2007a. "Demographic Trends and Energy Consumption in European Union Nations, 1960-2025." Social Science Research 36(3):855-872.

York, Richard. 2007b. "Structural Influences on Energy Production in South and East Asia, 1971-2002." Sociological Forum 22(4):532-554.

York, Richard. 2008. "De-Carbonization in Former Soviet Republics, 1992-2000: The Ecological Consequences of DeModernization." Social Problems 55(3):370-390.

York, Richard and Julius Alexander McGee. 2016. "Understanding the Jevons Paradox." Environmental Sociology 2(1):77-87.

York, Richard, Eugene A. Rosa, and Thomas Dietz. 2003a. "Footprints on the Earth: The Environmental Consequences of Modernity.” American Sociological Review 68(2):279-300. 
York, Richard, Eugene A. Rosa, and Thomas Dietz. 2003b. "STIRPAT, IPAT and ImPACT: Analytic tools for Unpacking the Driving Forces of Environmental Impacts." Ecological Economics 46(3):351-365.

Zhang, Chuanguo and Yan Lin. 2012. "Panel Estimation for Urbanization, Energy Consumption and $\mathrm{CO}_{2}$ Emissions: A Regional Analysis in China." Energy Policy 49(1):488-498. 